\title{
Enunciar-se, organizar-se, controlar-se: modos de subjetivação feminina no dispositivo da maternidade
}

\author{
Fabiana de Amorim Marcello \\ Universidade Federal do Rio Grande do Sul, Programa de Pós-Graduação em Educação
}

Neste artigo, utilizando-me principalmente da obra do filósofo francês Michel Foucault e de suas produções acerca do conceito de saber, relações de poder e modos de subjetivação, especialmente enquanto articulados no conceito de "dispositivo" (Foucault, 1995, 1998, 1999), busco discutir de que maneira um dispositivo da maternidade é organizado midiaticamente de forma a produzir modos de subjetivação feminina peculiares. Mais especificamente, o objetivo é analisar de que maneira o dispositivo da maternidade se ocupa da produção discursiva de sujeitosmãe ${ }^{1}$ por eles mesmos, constituindo, a partir disso, diferentes "modalidades maternas".

Entendendo "dispositivo" como conceito multilinear (Deleuze, 1999), pretendo, prioritariamente, descrever como se movimentam a linha de subjetivi-

${ }^{1}$ Tomado como objeto discursivo, o termo sujeito-mãe, nesse dispositivo, refere-se à diferenciação promovida pelos aparatos midiáticos entre mães-homossexuais, mães-adolescentes, mãessolteiras. Da mesma forma, "modalidades maternas" refere-se à maternidade homossexual, maternidade adolescente etc. dade e a linha de fuga (de fratura), enquanto linhas responsáveis por organizar estratégias de poder, formas de saber e contínuos convites para que o sujeito entre em relação de força consigo mesmo. Ou seja, interessa mostrar como indivíduos transformam-se em sujeitos-mãe nesse "dispositivo". Mas, embora não seja o foco principal deste artigo, pretendo também caracterizar, mesmo que brevemente, outros elementos que compõem o conceito em questão: curvas de visibilidade e regimes de enunciabilidade, já que se constituem como produtores genuínos de enunciados (e, por sua vez, de discursos); linhas de força, na medida em que estão intimamente relacionadas com a dimensão do poder e, por isso, atingem todos espaços do "dispositivo", naquilo que o poder tem de "onipresente", no sentido de se produzir a cada momento, a partir da complexa e estratégica relação entre todos os pontos de um "dispositivo".

Assim, pretendo discutir e problematizar tais questões filiando-me a estudos que articulam as áreas da educação e da comunicação, ou seja, partilhando do entendimento de que o próprio conceito de "educação" é ampliado, uma vez que os processos educa- 
cionais e formativos estão sendo exercidos também em outros espaços da cultura, como, no caso, por meio da mídia. Para tanto, pretendi fazer uma análise discursiva de dois conjuntos de materiais. O primeiro conjunto é composto por narrativas midiáticas retiradas de reportagens das revistas Veja ${ }^{2}$ e Caras $^{3}$ sobre certas mães famosas: Cássia Eller, Luciana Gimenez, Vera Fischer e Xuxa. As reportagens foram extraídas a partir do momento em que cada uma dessas mulheres tornou-se visível como mãe. No caso de Xuxa, as matérias foram selecionadas a partir de 1998; de Vera Fischer, 1992; de Cássia Eller, 1994; e de Luciana Gimenez, 1999, todas até março de 2003. O segundo conjunto de materiais é composto por uma gama de matérias retiradas de uma revista que se propõe ensinar e aperfeiçoar os cuidados e a atenção sobre a prática da maternidade: selecionei na revista Crescer $^{4}$ matérias publicadas no período de janeiro de 2001 a julho de 2002.

Para compreender como são produzidos os processos de subjetivação, concentro-me, principalmente, no que Foucault denominou de tecnologias do eu ou técnicas de si, cujo sentido é bastante preciso. Entende-se, pois, por esses movimentos

${ }^{2}$ Revista semanal, publicada pela Editora Abril, que aborda assuntos variados - desde notícias políticas (do país e do exterior), entrevistas com personalidades das mais diversas áreas (medicina, psicologia, literatura, comunicação, direito etc.), destaques de eventos sociais, polêmicas atuais e até mesmo indicações de livros, de peças teatrais e de filmes cinematográficos. A revista Veja é uma das mais tradicionais do país, estando no mercado há 35 anos.

${ }^{3}$ Revista semanal, publicada por uma editora própria, teve sua primeira publicação em 1990. Destina-se a relatar a vida, preferencialmente íntima, de artistas e pessoas famosas.

${ }^{4}$ Publicação mensal da Editora Globo desde 1990. Um dos motivos pelos quais essa revista foi escolhida para pertencer ao corpus de análise deve-se ao fato de que, dentre todas as publicações destinadas ao cuidado do infantil, a revista Crescer é a de maior vendagem no país (Crescer, 2001).
[...] os procedimentos, [...] pressupostos ou transcritos aos indivíduos para fixar sua identidade, mantê-la ou transformá-la em função de determinados fins, e isso graças a relações de domínio de si sobre si ou de conhecimento de si por si. (Foucault, 1997, p. 109)

Ou, ainda, modos de relação do sujeito consigo mesmo que

[...] permitem aos indivíduos, por conta própria ou com a ajuda de outros, certo número de operações sobre seu corpo e sua alma, pensamentos, condutas ou qualquer forma de ser, obtendo assim uma transformação de si mesmos, com o fim de alcançar certo estado de felicidade, pureza, sabedoria ou imortalidade. (Foucault, 1990, p. 48, tradução minha)

Assim, privilegio, para esta discussão, três dessas técnicas. A primeira está relacionada ao modo pelo qual o sujeito-mãe é convidado a controlar-se em suas atitudes. Há que se exigir do sujeito-mãe, portanto, o controle de seus atos (aquilo que pode falar e em relação a que pode falar) e também sobre seu corpo (sobre os alimentos que pode comer e a quantidade e hora em que o deve fazer). Ironicamente, esse processo de autocontrole muitas vezes é gerenciado, vigiado por outra pessoa, geralmente o parceiro.

Após, passo a argumentar a favor da técnica de auto-organização, a qual é sugerida pelo "dispositivo". Falo principalmente em relação ao tempo e à sua distribuição. Evidencia-se, nesse ponto, um processo pelo qual a maternidade só poderá ser plena e realizada de maneira eficaz na medida em que o sujeito-mãe se organize para tanto. Para exercer a função que lhe é designada por esse "dispositivo", é necessário que o sujeito-mãe enuncie a si mesmo como um ser organizado e preparado para enfrentar as inúmeras tarefas que lhes são dirigidas.

Por fim, discuto as formas pelas quais esse "dispositivo" se organiza de modo a promover movimentos em que o sujeito-mãe é conduzido a olhar para si mesmo. Constituindo-se como objetos visíveis para si, discuto de que maneiras as mães se enunciam como 
autoras de seus ditos e de sua maternidade e o quanto tal tarefa está ligada à atualização do próprio "dispositivo" em questão. Acredito ser essa uma técnica de si bastante característica dos aparatos midiáticos, tendo em vista que as formas de visibilidade e enunciação dos sujeitos-mãe exigem que estes se voltem para si e possam enunciar-se, muitas vezes, como exemplos de maternidade. Cabe, então, ao indivíduo-mãe falar sobre si mesmo como sujeito agora modificado, metamorfoseado, potencializado pela possibilidade de ser um sujeito-mãe.

\section{Controlar-se}

No "dispositivo" da maternidade, as linhas de subjetivação traçam e promovem técnicas diversas por meio das quais o sujeito-mãe é convidado a pensar sobre si mesmo para exercer de forma satisfatória sua prática materna. Nos aparatos de visibilidade em questão, não se trata apenas de evidenciar a importância de desenvolver tais técnicas, mas também de pontuar aquilo que pode, eventualmente, acontecer quando elas não são exercidas. Isso ocorre porque só faz sentido mostrar como essas técnicas são empreendidas por essa ou aquela modalidade materna à medida que, paralelamente, se mostra o quanto elas podem ser saudáveis ou prejudiciais ao desenvolvimento da criança. Dar visibilidade e enunciabilidade a esses modos específicos de ser sujeito-mãe é uma das formas que o "dispositivo" encontra de produzir práticas de maternização.

Dentre essas técnicas das quais falo, o autocontrole nos atos, nas atitudes e no modo de se conduzir é plenamente invocado; mais do que isso, é plenamente aconselhável, para que se possa almejar uma prática materna normativa. Gradativamente, o autocontrole do sujeito-mãe significará uma qualificação da maternidade. O "dispositivo" da maternidade, por suas linhas de subjetivação, cria uma lógica na qual relaciona a técnica do autocontrole ao cuidado com o outro (o filho).

Até mesmo os pensamentos do sujeito-mãe são alvo de controle. Mesmo grávida, a mulher-mãe é convidada a exercer sobre si um domínio constante em relação àquilo que lhe passa pela cabeça, já que, de alguma forma, isso pode interferir no desenvolvimento do feto. Quando grávida de cinco meses, Xuxa disse: "fico com medo de pensar coisas ruins, de arquear a sobrancelha ou ter aquele impulso de gritar. Quando se tem um novo ser dentro da gente, há que se exigir mais responsabilidade, há de se pensar coisas boas" (Xuxa..., 1998a). Tais atitudes evidenciam qualidades de uma prática materna. Esse autocontrole descrito sobre os pensamentos envolve a subversão de outros que, em princípio, poderiam prejudicar um ideal de maternidade. Ao voltar-se para si mesma e reconhecer-se como sujeito de uma maternidade específica, Xuxa enfatiza a relação entre maternidade e certos valores, certos conceitos socialmente construídos como bons. Promove-se, assim, a duplicação de uma lógica na qual esses bons pensamentos correspondem a uma prática materna responsável. Tal fato está intimamente ligado a uma visão de infância que deve ser protegida - infância constantemente invocada por esse "dispositivo".

Torna-se aconselhável que o indivíduo, quando na condição de sujeito-mãe, meça também suas palavras (expressadas em voz alta) e seus gestos. Como presente nessa ordem do discurso, tal sujeito não pode falar qualquer coisa, em qualquer lugar, a qualquer momento. Para falar de um possível relacionamento amoroso, há que se ter uma certa prudência nos ditos. Xuxa afirmava há algum tempo, sobre a especulação em torno de um possível caso amoroso: "Não é um caso, como chegaram a falar, e sim um namoro. [...] Mas tenho uma filha, não quero ficar falando em público" (Xuxa..., 2002).

Quando a revista Crescer entrevista mulheres de diferentes idades (de 18, 21, 25, 30 e 39 anos), em que "todas elas contam como a maternidade mudou suas vidas [...] diante de um novo amor: o filho" (Mães..., 2001, p. 40), a mãe de 25 anos informa: "tive que alterar totalmente a minha maneira de vestir e de falar - risquei os palavrões do vocabulário. E ensino conceitos religiosos para as crianças" (idem, ibidem). Trata-se então do empreendimento de uma outra gra- 
mática, uma outra forma de se conduzir e de se comportar, positivada pela maternidade. No ato de ter de medir as palavras, os sujeitos desse "dispositivo" indicam, paralelamente, a necessidade de um certo comedimento como fator de transformação de si. Os sujeitos, agora transformados pela prática materna e comedidos em suas atitudes, são evidenciados como sujeitos melhores, mais tranqüilos, serenos e responsáveis. A mãe em questão diz ainda que considera tais mudanças como os "pontos positivos" (idem, ibidem) da maternidade.

Não é apenas em relação ao vocabulário que há de se ter autocontrole; por exemplo, o sujeito-mãe também deve saber controlar sua ansiedade. Para a mãe de gêmeos é necessário um domínio sobre os sentimentos, pois isso intervirá no cuidado com as crianças. A revista Crescer indica que, nesse caso, "o importante é saber administrar a ansiedade de querer fazer tudo ao mesmo tempo" (Alegria..., 2001, p. 48). E adverte: "Vamos falar com franqueza: é impossível" (idem, ibidem). O autocontrole é o que permite que as tarefas saiam bem-feitas. Quando isso não acontece, ou seja, quando o autocontrole não é realizado, não apenas o sujeito-mãe ou a criança saem prejudicados, mas também a prática materna fica comprometida - e isso é sempre importante de ser assinalado. Por exemplo, logo que Sasha nasceu e foi para casa, "a menina chora[va] sem parar, de cólicas" (Choro..., 1998, p. 121). "A reação de Xuxa era de chorar junto, de desespero" (idem, ibidem). O que aconteceu? "O abatimento reduziu a quantidade de leite materno" (idem, ibidem). A falta do autocontrole prejudicou o cuidado com a amamentação e, conseqüentemente, o cuidado com a filha.

Mesmo antes de engravidar, o sujeito-mãe deve ter o domínio sobre si. A revista Crescer adverte: "Se você pretende ficar grávida em breve e está com alguns quilinhos acima do seu peso, avalie com seu médico a necessidade de emagrecer antes de encomendar o bebê" (O desafio..., 2001, p. 20). Afirma ainda a revista que "esta é a atitude mais sensata, pois infelizmente muitas [mulheres] só despertam para os problemas ligados aos maus hábitos alimentares quan- do o bebê já está a caminho" (idem, ibidem). Assim, as linhas de subjetivação buscam capturar o sujeito no sentido da prudência, da previsão e, claro, do controle que ele deve exercer sobre seu corpo mesmo antes de engravidar, para ser um sujeito-mãe normativo desse "dispositivo": controle que, nesse caso, circula através da mera possibilidade de a mulher vir a se tornar mãe. O "dispositivo" da maternidade compõe, assim, um sentido em que o sujeito há que se reconhecer como fonte manifesta de problemas e riscos.

É possível entender o quanto o corpo é alvo das linhas de subjetivação que o constroem como efeito de um conjunto de técnicas de si. É sobre o corpo que se organizam sentidos pelos quais o sujeito-mãe é capaz de transformá-lo, modificá-lo, atuar sobre si mesmo em virtude de uma prática materna normativa. Há uma ligação profunda entre corpo feminino, corpo materno e maternidade. Seja como fonte de alimento, seja como subsistência do feto, inúmeras prescrições são feitas à mãe para que ela efetivamente entenda que esse corpo não é só seu, tendo em vista que é do controle desse corpo que vai depender a saúde de seu filho.

"A quantidade de calorias ingeridas não deve ser a única preocupação da gestante. A qualidade de sua alimentação é fundamental para garantir ao bebê um desenvolvimento adequado" (idem, p. 23). Isso significa "dar preferência aos alimentos in natura, montar pratos coloridos, já que a cor dos alimentos está relacionada com os nutrientes que eles possuem" (idem, ibidem), ou seja, "comer várias vezes ao dia em pequenas quantidades, beber bastante água e começar as refeições com as saladas, o que sacia a fome antes de chegar aos pratos mais calóricos" (idem, ibidem). O importante é que "vitaminas não engordam e sua carência pode ser prejudicial ao bebê" (idem, ibidem). Trata-se de enunciações que certamente poderiam ser deslocadas para qualquer revista de cuidados com o corpo feminino. Aqui, porém, esses cuidados são propostos em nome de uma qualidade nutricional ligada ao feto e ao seu desenvolvimento.

Pode acontecer de essa informação (da dependência de um corpo que não é só seu) não ser sufi- 
ciente. Para tanto, o "dispositivo" organiza sentidos nos quais o controle do corpo deve ser realmente efetuado, seja em nome do filho, seja em nome da feminilidade exigida. Recomenda-se que, na gravidez, a mãe faça exercícios físicos, pois eles seriam "ótimos aliados no combate aos quilinhos extras" (idem, p. 20), e também "queimam a gordura e aumentam a massa muscular" (idem, ibidem) e "de quebra contribuem para relaxar, diminuem a ansiedade e trabalham a consciência corporal" (idem, ibidem). Há que se exigir o controle, primeiro em nome do filho e depois em nome de si mesma.

Outra modalidade materna, que talvez possa ser chamada de "finalmente-mães", corresponde àquelas mulheres que, depois de longas tentativas fracassadas, resolveram "dar uma ajuda à natureza" (Finalmente..., 2001, p. 52) e efetuar a fertilização in vitro; também essa modalidade mostra o cuidado de si como cuidado do outro. Uma dessas mães, Jussara Fleury, de 37 anos, afirma: "a expectativa era enorme, mas a notícia de uma dupla gravidez foi maior ainda. Eu tinha perdido um bebê e ganharia dois. Tratei de segurá-los, seguindo com o maior cuidado todas as recomendações médicas" (idem, ibidem, grifos meus). Ela informa quais eram tais recomendações: "não subir escadas, evitar caminhadas longas, ficar de repouso nos últimos quatro meses" (idem, ibidem). E finaliza: "não importava, eu só pensava no prazer [que ela ainda não conhecia] de ser mãe" (idem, ibidem). Ainda assim, uma das outras mães afirma que, mesmo ansiosa para o parto, nos últimos dias de gravidez teve que se acalmar, pois sabia que um dia a mais no útero [significava para seu filho] um dia a menos na incubadora (idem, p. 53). Natural e artificial entram em tensão, em luta, para a produção de práticas de maternização. Se, por um lado, o fato de realizar uma fecundação em laboratório pode servir como argumento para comprovar a tendência da mulher a ser mãe, por outro a incubadora é encarada como uma possibilidade artificial (em detrimento do útero, abrigo natural do bebê) de subsistência do feto e, portanto, não desejável. Ao reconhecer o corpo materno como locus acolhedor natural de um feto, a mãe é vista por si mesma como responsável por "se- gurar" os filhos em seu ventre.

Interessa também propor a forma determinada de um corpo: um corpo saudável, dependente do modo como o sujeito-mãe o conduz. Se, durante a gravidez, aquilo que a mãe faz com o corpo é importante para o bom desenvolvimento do feto ou para sua subsistência, no caso das mães que já pariram seus filhos aquilo que elas fazem com seu corpo pode estar relacionado com o desenvolvimento saudável da infância de suas crianças.

No caso da atriz Vera Fischer, o autocontrole de seus atos está referido, principalmente, ao problema da dependência química. A revista que mostra um dos momentos em que a atriz se enclausurou em uma clínica para dependentes destaca em letras sobressalentes: "Para não perder o direito de visitação do filho Gabriel, ela não brinca o carnaval e retoma o tratamento na clínica" (O retiro..., 1998). A atriz informa: "é importante estar aqui esta época do ano. O Carnaval é muito tentador e na clínica não tenho contato com esta festança" (idem). Foi por "livre e espontânea vontade" (idem) que a atriz aportou na clínica de reabilitação, "desistindo de todos os planos" (idem) daquele carnaval. Tal espaço foi dedicado também a uma espécie de reforço para suas aulas de "“acertividade', que consistem em 'aprender a dizer 'não' aos prazeres proibidos" (idem). Acrescenta ainda a diretora da clínica, a respeito de Vera: "ela é muito corajosa e tem predisposição para mudanças, acho que em pouco tempo estará definitivamente equilibrada e pronta para uma nova luta [no caso, para um outro pedido de guarda judicial de seu filho]" (idem). O cuidado de si significa dizer não às tentações, às drogas, pois isso significará que a atriz está disposta a viver uma vida mais regrada e tranqüila e, igualmente, que ela agora pode vir a ter condições de cuidar de seu filho: maternidade e drogas, cuidado de si como cuidado do outro.

Trata-se aqui também de uma relação agonística ${ }^{5}$

${ }^{5} \mathrm{O}$ adjetivo "agonístico" diz respeito a uma "relação que é, ao mesmo tempo, de incitação recíproca e de luta", ou seja, "me- 
consigo mesmo (instaurada a partir das linhas de força), em que se deve lutar ativamente contra os prazeres proibidos. Em relação aos gregos, Foucault afirma que "somente instaurando, em relação aos prazeres, uma atitude de combate, é que se pode conduzir-se moralmente" (Foucault, 1998, p. 62). De fato, nesse "dispositivo" há um entrelaçamento entre técnicas de si e um código moral que, então, lhe dá sustentação. Mais do que isso, certas técnicas de si constituem-se elementos do código moral desse "dispositivo", de forma que a maneira como os sujeitosmãe conduzem a si mesmos irá afirmar ou não uma "moralidade em seus comportamentos" (idem, ibidem).

A cantora Cássia Eller, perguntada se havia parado com as drogas por causa do filho, responde:

Eu cheirava muita cocaína. Parei total, graças a Deus. Fiquei um tempo sem beber também, e isso me fez bem. Não foi nem exatamente por causa de Chicão que eu parei, meu corpo não estava mais agüentando. Durante a gravidez, parei porque, milagrosamente, enjoei de cigarro, café, maconha, de tudo. Aí o Chicão nasceu, amamentei e depois caí na farra de novo. (Drogas..., 2002, p. 80)

Pressupõe-se que seria por causa da criança que ela teria parado com as drogas. Tendo em vista que isso não foi evidenciado, busca-se assinalar que o motivo pelo qual o sujeito-mãe temporariamente tornou-se saudável não está relacionado com o seu filho ou com o fato de estar grávida. É necessário tal movimento, operado pelo sujeito que enuncia a si mesmo, já que a gravidez é um campo no qual o "dispositivo" da maternidade articula inúmeros saberes, inúmeros cuidados. Porém, é possível que o sujeito-mãe resista, escape, fuja dessa forma de dominar seus comportamentos e seu corpo em nome do filho, desde que evidencie, enuncie que assim o faz. Já que é importante para esse "dispositivo" que o sujeito seja capaz

nos de uma oposição entre termos que se bloqueiam mutuamente do que de uma provocação permanente" (Foucault, 1995, p. 245). de se enunciar, as curvas de visibilidade e os regimes de enunciabilidade mostram o caminho e os critérios pelos quais ele deve se ver, se dizer e se julgar. Ao enunciar que "não foi exatamente por Chicão" que ela parou com as drogas, Cássia Eller faz de si mesma objeto visível, avalia o que já foi avaliado, julga o que já foi julgado, externalizando uma atribuição de valor em seus atos que foi antecipadamente composta pelas linhas de força desse "dispositivo" (principalmente aquelas ligadas à composição da norma).

Ironicamente, há momentos em que mesmo o autocontrole do sujeito-mãe deve ser controlado. Ao parceiro ou pai da criança cabe essa tarefa. Em um evento de Carnaval que levava o seu nome ("Carnaxuxa"), a apresentadora, "após consultar a pediatra" (Xuxa..., 1998b), comandou um baile de Carnaval. Xuxa, então grávida de quatro meses, revelava-se uma gestante que "não demonstra[va] cansaço, nem indisposição, sintomas comuns ao início de uma gestação" (idem). Assistindo à "performance da mulher" (idem), Luciano Szafir avisa aos repórteres: "Não acho que ela está pulando muito. Está comportada. De qualquer maneira, fico por aqui, regulando" (idem, grifo meu).

A propósito de Vera Fischer e da internação que fez para manter a guarda de seu filho, o ex-marido Felipe Camargo dá uma entrevista exatamente na mesma edição da revista Veja, dizendo: "é claro que se ela estivesse ótima, se tratando, não pediria a suspensão da visita. Poderíamos entrar em um acordo mais brando. Ela, porém, só entende as coisas desta maneira" (Felipe..., 1998). O sujeito-pai é um dos que têm legitimidade para controlar e vigiar se o autocontrole da mulher está efetivamente sendo realizado. É ainda o sujeito-pai que insiste em domesticar a mulher e contribuir para que ela compreenda que somente dessa forma sua prática materna pode ser desenvolvida plenamente. Felipe Camargo acrescenta: "Desde que ganhei a guarda de Gabriel só consegui coisas positivas para todas as nossas vidas. O Gabriel está ótimo, saudável, virou uma criança mais serena, [...] e a Vera deu o primeiro passo para curar a dependência química" (idem). $\mathrm{O}$ fato de a criança ter se afasta- 
do da mãe drogada permitiu que o menino tivesse se tornado mais sereno, tranqüilo. Do mesmo modo, ao buscar "conscientizar" a mãe da importância desse equilíbrio, o sujeito-pai instaura sentidos que a conduzem a uma melhoria. Há que se promover assim uma suposta "conscientização" dos sujeitos, de que aquilo que ele faz com seu corpo interfere na sua prática materna, seja positiva, seja negativamente. O importante é assinalar, constantemente, o quanto práticas do corpo feminino continuam em relação com práticas do corpo materno.

\section{Organizar-se}

No processo de organizar-se estão envolvidas estratégias nas quais cria-se o sentido de que, assim procedendo, o sujeito-mãe terá uma capacidade maior de desenvolver uma prática materna normativa. A faculdade de organizar-se, quando plenamente desenvolvida e desempenhada, faz com que a prática materna se torne potencializada. Tal fato é encarado positivamente por esse "dispositivo", na medida em que suas linhas de subjetivação desenvolvem os meios para que o sujeito-mãe se volte para si mesmo, olhe ao seu redor e perceba o quanto as ações vinculadas ao ato de estar plenamente organizado no tempo e nas atividades podem ser benéficas para o crescimento de seu filho(a).

Nessa discussão, um tema que ganha centralidade é a organização entre atividades maternas e trabalho. Há uma constante tensão enunciada pelo sujeito que avalia a si próprio em relação às atividades que deve desenvolver como mãe e como profissional. Xuxa diz: "Depois do parto, achei que conseguiria fazer tudo, regime, ginástica, trabalhar e ainda ser mãe dedicada. Não dá para conciliar trabalho e amamentação ou passar as noites dando atenção para a minha filha e, no dia seguinte, acordar bem-disposta" (A melhor..., 1998). A mãe de 29 anos afirma: "Antes de engravidar, eu trabalhava na loja de uma amiga, mas quando Diogo nasceu, parei para cuidar dele. Vou recomeçar agora, em outra loja, mas das 16horas às 22horas. Não quero mexer na vidinha deles" (Mães...,
2001, p. 40-41). Há alguns prejuízos nessa mudança: "Não vou poder mais jantar com o meu marido, mas prefiro abrir mão disso para poder continuar mais perto dos meus filhos" (idem, ibidem). Trata-se da busca por fixar sentidos entre prática materna e trabalho, e a incongruência entre os dois. Assim, ao constantemente ser colocada em questão por essas mulheres, a relação entre trabalho e a maternidade - evidenciada nos seus exemplos individuais (pertencentes à classe média e alta) -, está implicada muitas vezes de modo negativo ou prejudicial à prática materna. $\mathrm{O}$ fato é que se colocam lado a lado duas práticas de ordens diferentes e cria-se um valor correspondente entre elas.

A mãe de 39 anos afirma: "Acho muito difícil conciliar filho e trabalho quando se prioriza o primeiro" (idem, ibidem). Tais enunciações permitem que o sujeito-mãe possa afirmar: "se eu tivesse que escolher entre marido e filho, não teria dúvida: ficaria com o segundo. O homem percebe isso, não deve ser agradável ficar em segundo plano" (idem, ibidem). Como é possível estabelecer uma relação comparativa entre maternidade e trabalho e, posteriormente, entre maternidade e casamento?

O que fazer nos horários livres é também tema e motivo para invocar a auto-organização do sujeitomãe. Trata-se de mostrar não apenas o sujeito que se auto-organiza em função do filho, mas o quanto tal técnica se torna importante para si mesma e para as suas possibilidades de tornar-se um indivíduo melhor. Mostrar, dar a ver as mudanças pelas quais esse sujeito passou é evidenciar a proximidade com uma prática materna normativa. "Parei de pensar em mim, agora só me preocupo com o Pedro. Antes de ter filho, eu usava todo o meu tempo livre para malhar. Agora, não, só quero voltar correndo para casa para ficar com ele" (idem, p. 41). A mãe ainda reflete: "estou sempre preocupada, pensando se estou fazendo as coisas certas" (idem, ibidem). Há, nessa enunciação, uma evidente subversão e uma fuga em relação ao imperativo de um cuidado temporário e específico com o corpo. Ao buscar fazer "a coisa certa", o "dispositivo" captura o sujeito-mãe a partir das relações de força que conjugam normatividade e tempo dedicado ao seu 
filho. O "dispositivo" da maternidade organiza sentidos de forma a evidenciar que essa conjugação não implica a ausência de cuidado de si. Ao contrário, o cuidado de si é apenas transferido, deslocado do cuidado com o corpo para o cuidado com o filho.

Para determinadas modalidades maternas, a tarefa de auto-organização exige uma série de cuidados e atenções paralelas. Para que isso possa ser efetuado, é necessário que se aplique um olhar atento sobre o outro, sobre as qualidades e individualidades desse outro, que é o filho. Para organizar-se é preciso despender um tempo sobre o filho, conhecer minuciosamente todas as suas características. Para as mães de gêmeos, por exemplo, é exigido "conhecer as diferenças entre os gêmeos, aprender a perceber cada detalhe nos cuidados com eles, mudar a rotina quando necessário, organizar-se para atender às novas exigências: tudo isso as mães que conversaram com a Crescer aprenderam na prática" (Alegria..., 2001, p. 48). Ou seja, "atender a um de cada vez é a melhor forma de controlar a situação e é bom para os bebês também" (idem, ibidem). É importante apontar o quanto essas técnicas são envolvidas por sentidos que comprovam a legitimidade de tal exercício. Ao trazer outras mães que passaram por práticas e obstáculos semelhantes, busca-se uma espécie de relação entre os sujeitos, fazendo-os entender que se de fato algo não dá certo, é porque talvez não tenha havido organização suficiente ou satisfatória para isso. As linhas de subjetivação traçam certas lógicas, segundo as quais aos sujeitos-mãe cabe a responsabilidade do controle das situações e do bem-estar do filho, graças às maneiras pelas quais eles devem efetivamente se organizar.

O sujeito-mãe auto-organizado possibilita enunciar-se como criador de um sem número de procedimentos denominados adequados. "Preocupada em evitar a ciumeira entre os irmãos, [...] Simone Leyser [...] adotou desde cedo uma atitude muito prática: entre uma mamada e outra procurava estabelecer um intervalo de meia hora para curtir o colo com cada uma [das filhas gêmeas] em separado" (idem, ibidem, grifos meus). Outra dica da mãe Simone: "quando quero ninar as duas ao mesmo tempo, faço diferente: levo as meninas para a minha cama, deito entre elas e ficamos abraçadas e juntinhas até que adormeçam" (idem, ibidem). Trata-se de evidenciar a maneira pela qual os sujeitos-mãe são convidados a refletirem sobre si mesmos, sobre suas práticas maternas e sobre quanto isso pode acarretar como resultados positivos para seus filhos. Convocados a auto-organizarem-se como sujeitos assujeitados por esse "dispositivo", os sujeitos-mãe parecem querer descobrir mais e mais estratégias para driblar sofrimentos, angústias e tristezas do filho. Produzem-se e enunciam-se como criadores de seus ditos, de suas estratégias e de sua maternidade.

Organizar-se diz respeito também a um aumento no contato entre mãe e filho; diz respeito à escolha, à distribuição ordenada das atividades, às formas específicas de agir e de se comportar, de modo que o cuidado de si é articulado como cuidado do outro. No caso de Xuxa, "ela mesma se surpreendeu ao descer com a filha no colo para tomar o café da manhã no restaurante à beira da piscina do Hotel Acapulco Princess" (Xuxa..., 1999). Ela diz: "Desde que era modelo não fazia isso. Entre dormir e comer, preferia dormir. Agora é diferente. Não vou ficar trancada com a Sasha dentro de um quarto de hotel. Quero curtir todos os momentos com ela" (idem). A mãe prefere acordar cedo e passar mais tempo com sua filha: olhando para si mesma, organizando seus gestos, o sujeitomãe desse "dispositivo" evidencia que ela e sua filha têm mais a ganhar com o tempo que passam juntas.

No caso de Luciana Gimenez, cuidado de si e cuidado do outro compõem uma outra lógica. As linhas de força traçam sentidos relacionados à idéia de que o cuidado por ela dispensado a seu filho é um "cuidado de si" ligado ao lado financeiro. Enunciar, pelas revistas, a maternidade-negócio é dizer que ela efetivamente representa algo não-valorizado. É essa outra forma de relacionar o cuidado que faz de tal maternidade-negócio algo menos valorizado e passível de julgamento. As revistas buscam compor sentidos específicos a partir da narração da maternidade de Luciana Gimenez. Aliadas a enunciações já referi- 
das neste artigo, como a de que a apresentadora tenta proteger o "patrimônio acomodado na barriga de seis meses"; ou sobre quantos milhões de dólares (adquiridos da pensão alimentícia paga a seu filho) são necessários para completar sua felicidade, somam-se outras: "[Luciana] continua no papel de mãe extremada de Lucas, que lhe garante uma pensão de 10.000 dólares por mês" (Como..., 2000, p. 56); ou de que, confirmada a paternidade de Mick Jagger, a apresentadora poderia, então, dar "uma garfada" (Ele tenta..., 1999, p. 115) no patrimônio do cantor. Ironiza-se uma maternidade que resiste a incorporar-se a um padrão. Se geralmente o cuidado de si como cuidado do outro é articulado nesse "dispositivo" da maternidade para mostrar as qualidades de abdicação, zelo, amor e preocupação necessários para a constituição de uma maternidade normativa, nesse ponto o cuidado do outro como cuidado de si tem valor e enunciação diferenciados. O "dispositivo" assim efetiva-se na tarefa de constituir práticas de maternização, na medida em que faz questão de diferenciá-la de uma lógica específica que ele mesmo ("dispositivo" da maternidade) coloca em funcionamento.

\section{Enunciar-se}

A técnica de si ligada ao fato de enunciar-se é uma das mais privilegiadas nas revistas que analisei. Nesses espaços midiáticos, a maternidade ganha visibilidade e enunciabilidade à medida que pode, paralelamente, ser comprovada pelos sujeitos-mãe envolvidos. O sujeito-mãe pode ser convidado a expressar-se, a falar sobre si e, reconhecido como criador de seus ditos, demonstrar as transformações que a prática materna individual acarretou em sua vida.

Uma vez que o sujeito-mãe considera-se efetivamente autor desses ditos e de sua maternidade, age como se aquilo que pronuncia fosse mero resultado, mero efeito de uma prática individual. A maternidade é apresentada como um franco e gratuito falar, que apenas "expressa" certas vivências maternas específicas. Há que se compreender que esses ditos refratam as linhas de força do "dispositivo", que, aliadas às linhas de subjetivação, promovem novos saberes e novas "verdades" sobre o sujeito-mãe e sobre a prática materna. Há que se considerar que, para serem pronunciadas, tais falas e tais saberes, tais voltas para si mesmos, precisam de condições, de possibilidade, as quais são dadas pelo "dispositivo" da maternidade. Nesse sentido, as enunciações que Xuxa promove sobre seu amor infinito de mãe são profundamente esclarecedoras:

\footnotetext{
Minha mãe vive falando que só quando se tem um filho se entende o que é saber dar sem receber nada em troca. Não é que a gente se anule, mas esse amor preenche tudo, não precisa de mais nada. Se eu conseguir ser metade de tudo o que ela é, vou alcançar todo o equilíbrio e a sabedoria que preciso para cuidar da Sasha. (O novo..., 2000, grifos meus)

[...] a maternidade mudou a minha vida. Hoje sou muito mais feliz. Se as mães amarem mais seus filhos, poderemos fazer um mundo bem melhor; [...] e, quanto a mim... Me tornei uma pessoa melhor depois que Sasha nasceu. (Sasha..., 2001, grifos meus)
}

[...] não entendo como consegui viver antes de ter a Sasha; me divirto ainda mais quando vejo minha filha alegre.

(Show..., 2000, grifos meus)

Esses pressupostos e enunciações individuais, pronunciados pela apresentadora, adquirem um estatuto de verdade, constituem-se efetivamente como saberes acerca da maternidade. Ao mesmo tempo, tais enunciações tornam-se totalizadoras, na medida em que ilustram (e são tomadas como) parte de uma mesma maternidade. Aqui, universal e particular articulam-se dentro dos discursos, de forma a evidenciar diferentes significações em torno de uma determinada representação materna que se torna, então, desejável. Uma representação que só pode ser pensada e articulada uma vez que é colocada em discurso e, poderíamos dizer, uma vez que é vista no âmbito de um "dispositivo".

O que o sujeito enuncia de si mesmo é nada menos do que aquilo que as curvas de visibilidade e os 
regimes de enunciabilidade do "dispositivo" da maternidade permitiram que ele fizesse. Há que se considerar, para tanto, que a qualificação entre melhor ou pior, que o sujeito é convidado a fazer, se dá no sentido de que tal qualificação está anteriormente articulada aos enunciados que esse "dispositivo" coloca em funcionamento. O que o sujeito conhece e sabe de si mesmo não vem, pois, comprovar que os saberes são naturais e produzidos a partir da relação particular, individual, que cada sujeito-mãe estabelece com seu (sua) filho(a) (afinal, os sujeitos-mãe enunciam-se efetivamente como pessoas melhores por causa de sua prática materna). Eles evidenciam que são saberes-efeito de uma combinação de elementos, análoga àqueles produzidos pelas curvas de visibilidade e pelos regimes de enunciabilidade do "dispositivo". "Para que o autoconhecimento seja possível, então, se requer uma certa exteriorização da própria imagem, um algo exterior, convertido em objeto, no qual a pessoa possa ver a si mesma" (Larrosa, 1995, p. 59, grifo meu).

Xuxa ainda acrescenta: "Me vejo como uma pessoa mais forte, sei o que eu quero. Antes, ficava na dúvida, achava que deveriam tomar as decisões por mim. Agora estou mais firme. A palavra 'acho' quase não uso mais. O futuro de Sasha está nas minhas mãos. Depois do nascimento dela, passei a pensar no hoje e no amanhã. Antes vivia o momento" (Xuxa..., 1999). Não é o sujeito-mãe individual o autor dessa maternidade, mas o efeito da combinação entre as curvas de visibilidade e as linhas de subjetivação que, de fato, orientam seu olhar sobre si mesmo. A mídia, portanto, não se constitui como um mero espaço em que as mães conseguem dar visibilidade e enunciabilidade aos saberes e à normatividade, mas como um espaço que igualmente produz, por suas linhas de subjetivação, formas pelas quais elas se reconhecem nesses saberes, se reconhecem nessa normatividade e podem efetivamente enunciar-se (e serem enunciadas) como sujeitos desse "dispositivo".

Sobre as modalidades maternas que precisaram de auxílios médicos para engravidar, uma das mães fala de sua persistência e, ainda, dos motivos de tal persistência: "passeando pelas ruas, eu observava jovens, pobres, grávidas, sem condições de cuidar do filho que viria, e eu, que podia dar tudo, não conseguia engravidar. Isso me incomodava profundamente e, ao mesmo tempo, era um dos motivos para não desistir" (Finalmente..., 2001, p. 53, grifos meus). A manchete desse depoimento vem escrita em letras maiores, em vermelho "de olho na barriga alheia" (idem, ibidem). A partir de enunciações como essas, o processo agonístico de construção das modalidades maternas pode ser evidenciado. Com a instauração dessa cadeia de diferenças que se afirma (jovens, pobres, grávidas, sem condições de cuidar do filho que virá), a mãe dada a si mesmo como objeto visível encontra condições de se enunciar como um sujeito-mãe mais legítimo e mais merecedor da maternidade. Assim, novos sentidos são compostos a partir da fala comovedora da mulher que muito quer mas não consegue engravidar, e que vê naquele "outro" (sujeitomãe adolescente/pobre) a sua afirmação; mais do que isso, vê a licitude de sua maternidade. Modalidades maternas são postas lado a lado, permitindo facilmente um processo de hierarquização entre elas.

Sobre essa modalidade materna (de mães com dificuldades de engravidar) há uma delas que enuncia: “engravidei na primeira tentativa, fiquei eufórica, só que logo depois sofri um aborto espontâneo, um choque. Mas aí, eu já tinha experimentado a sensação de estar grávida - um presente de Deus!" (idem, ibidem). O interessante é problematizar que para essa modalidade materna mais vale uma gravidez falha do que o fato de não engravidar. Parece que é com essa gravidez interrompida que determinados aspectos de sua feminilidade podem ser comprovados. O que está em jogo, contudo, não é efetivamente ser mãe ou não, mas ter a possibilidade de ser mãe. O prazer, aqui, não está na maternidade em si, mas no fato de poder torna-se mãe; vir a ser mãe.

Essas mulheres contam suas histórias, falam dos muitos anos em que tentaram engravidar, algumas durante cinco, onze e até treze anos. A "ajudinha que a medicina deu à natureza" (idem, ibidem) permite que essas mulheres "sedentas" por maternidade não te- 
nham apenas um filho (como acontece em grande parte nos casos de reprodução convencional), mas duas, três e até quatro crianças de uma só vez. Em suas falas, assinalam os movimentos que fizeram para "tornar esse sonho realidade" (idem, ibidem). Muitas iam freqüentemente a consultas fora de suas cidades e até de seus estados, sofreram abortos espontâneos, mas mesmo assim persistiram.

Os textos bíblicos propunham que a infertilidade da mulher (Sara, Rebeca e Raquel) era um castigo divino e, nessa condição, era necessário "pedir" o filho à imagem hierárquica do patriarca (GoldmanAmirav, 1996). Nos casos descritos, as mulheres, reconhecendo-se como corpos em falta, "pedem" seus filhos ao saber médico; recorrem a este para poder enunciarem-se mulheres mais felizes, mais completas. São esses saberes médicos, marcados em seus corpos, que thes permite descobrir, olhando-se como objetos do "dispositivo", que "a realização máxima de uma mulher é ser mãe" (idem, p. 55) ou que o parto é um momento sublime (idem, p. 53).

Da mesma forma, embora essas mulheres enfatizem os períodos de profundas tristezas, comoções, dores pelos quais passaram a cada vez que perdiam um filho, elas nos mostram também que tais momentos puderam ser superados pela possibilidade de tentar mais uma vez. Trata-se, portanto, de sentidos que impelem, convidam à emoção e, junto a isso, tramam e engendram outros saberes específicos sobre o que é a maternidade, sobre o que é ser mãe, sobre a medicina e sobre, até mesmo, o filho desejado. No processo de voltar-se para si, constitui-se ou possibilita-se a construção de novos saberes normativos.

As técnicas médicas referidas propiciam o reforço a um tipo de ordem social na qual o recurso à "solução médica é mais adequado do que a consideração de soluções sociais alternativas" (Barbosa, 2000, p. 224). Busca-se romper com a dualidade naturezaartificialidade. Como objetos discursivos, as mulheres afirmam que sua gravidez não foi totalmente artificial, mas apenas precisaram de uma ajuda médica para o fato "natural" de ser mãe. Tais fatores reforçam ainda mais o vínculo entre mulher e reprodução, como função e como característica incontestável de seu ser.

Nesse sentido, o "dispositivo" da maternidade e o "dispositivo" pedagógico da mídia entrelaçam-se para a veiculação de procedimentos que colocam o sujeito-mulher como protagonista de suas falas. Mais do que isso, o que interessa discutir é a constituição de um sujeito que aprende a se ver e a se dizer a partir de um "dispositivo" que produz, por suas linhas de subjetivação, práticas que medeiam a relação do sujeito-mãe consigo mesmo. ${ }^{6}$ Falamos, portanto, da produção de "dispositivos" que atuam de forma ativa na fabricação de indivíduos, do seu assujeitamento. Há que se considerar que tais falas não apenas refratam o trabalho das linhas, mas também as atualizam; atualizam o próprio “dispositivo". Positivadas pelas linhas de subjetivação, elas fazem com que o sujeito fale de si mesmo e, com isso, ele não apenas se dê a ver, mas modifique e reorganize o objeto que é.

\section{Considerações finais}

Neste artigo, busquei argumentar como um "dispositivo" organiza-se, como produz e como incita o aprendizado de um conjunto de conhecimentos, de uma gama de saberes para a prática materna. Tentei caracterizar, especialmente, como esse "dispositivo" promove, incita e engendra suas linhas de subjetivação, de modo que o sujeito-mãe seja convidado a falar de si e a estabelecer uma relação reflexiva consigo mesmo. As linhas de subjetividade tecem estratégias pelas quais o sujeito pode efetuar um processo de objetivação de si mesmo e de sua modalidade materna, a partir da visibilidade que tem de si e de sua modalidade materna.

Contudo, não desconsiderei o fato de que, para efetuar essa volta para si mesmo, o sujeito-mãe se utiliza, inúmeras vezes, dos saberes e da normatividade elaborados e historicamente construídos pelo

\footnotetext{
${ }^{6}$ Essa discussão sobre a constituição do sujeito pedagógico
} e da forma como ele aprende por um dispositivo é discutida em Larrosa (1995, p. 36) e Fischer (2000, p. 12). 
"dispositivo" da maternidade. Há, portanto, a instituição de uma gramática, de uma sintaxe específica que aos sujeitos-mãe cabe usar, aprimorar e atualizar. Considero que, assim como os saberes e a normatividade articulada por esse "dispositivo" são históricos, o mesmo se pode dizer dos modos de subjetivação por ele propostos. Afirmo, portanto, que os modos de se comportar, de se ver e se dizer do sujeito-mãe são contingentes: o modo de ser mãe é histórico.

Tornar-se objeto de si mesmo só tem sentido na medida em que uma determinada modalidade normativa adquiriu certo status e certa legitimidade no interior do "dispositivo". É em relação a essa objetivação que as linhas de subjetivação constituem seus sujeitos. É sobre essa normatividade que eles são convidados a falarem de si - seja para comprová-la, seja para adequar-se a ela, seja para dela escapar. Trata-se de um movimento que, ao mesmo tempo em que produz uma verdade sobre a normatividade, ajuda a dar sentido a ela, contribuindo para que certos sentidos sejam legitimados, propagados e atualizados a favor de outros, por sua vez negados, excluídos, barrados.

FABIANA DE AMORIM MARCELLO, mestre em educação pela Universidade Federal do Rio Grande do Sul e membro do Núcleo de Estudos sobre Mídia, Educação e Subjetividade (NEMES), coordenado pela professora Rosa Maria Bueno Fischer. Como doutoranda na mesma instituição e bolsista do CNPq, pesquisa as relações entre infância, imagem e cinema. Publicou recentemente: O conceito de dispositivo em Foucault: mídia e produção agonística de sujeitos maternos (In: Educação \& Realidade"Dossiê Foucault", Porto Alegre, v. 29, nº 1, jan./jun., 2004, p. 199-213.).E-mail: famarcello@uol.com.br

\section{Referências bibliográficas}

A MELHOR tacada de Xuxa, (1998). Caras, São Paulo, edição $265, n^{\circ} 49$, ano 6,4 dez.

ALEGRIA em dose dupla, (2001). Crescer, São Paulo, nº 94, p. 48-50, set.

BARBOSA, R. M., (2000). Relações de gênero, infertilidade e novas tecnologias reprodutivas. Estudos Feministas, Florianópolis: CFHC/CCE/UFSC, v. 8, n 1 , p. 212-228.
CHORO daqui, choro de lá, (1998). Veja, São Paulo, edição 1.566, p. 12,30 set.

COMO uma virgem, (2000). Veja, São Paulo, edição 1.675, p. 156, 15 nov.

CRESCER, (2001). Disponível em: <http://www.crescer.globo. com.br>. Acesso em: jan.

DELEUZE, G., (1999). Que és un dispositivo? In: BALIBAR, E., DREYFUS, H., DELEUZE, G. et al. Michel Foucault, filósofo. Barcelona: Gedisa, p. 155-163.

DROGAS e agonia no auge da vida, (2002). Veja, São Paulo, edição 1.733 , p. 79-82, 9 jan.

ELE TENTA, ele tenta, (1999). Veja, São Paulo, edição 1.582, p. 115,27 jan.

FELIPE Camargo em luta pelo filho, (1998). Caras, São Paulo, edição 225 , ano $5, n^{\circ}$ 9, 27 fev.

FINALMENTE mães, (2001). Crescer, São Paulo, nº 90, p. $52-$ 55 , maio

FISCHER, R. M., (2000). O dispositivo pedagógico da mídia: relatório final de pesquisa. Porto Alegre: Faculdade de Educação da Universidade Federal do Rio Grande do Sul.

FOUCAULT, M., (1990). Tecnologias del yo y otros textos afines. Barcelona: Paidós.

(1995). O sujeito e o poder. In: DREYFUS, H., RABINOW, P. et al. Michel Foucault: uma trajetória filosófica (para além do estruturalismo e da hermenêutica). Rio de Janeiro: Forense Universitária, p. 231-249.

(1997). Subjetividade e verdade. In: FOUCAULT, M. Resumo dos cursos do Collège de France (1970-1982). Rio de Janeiro: Jorge Zahar, p. 107-115.

, (1998). História da sexualidade - v. 2: o uso dos prazeres. Rio de Janeiro: Graal.

, (1999) História da sexualidade - v. 1: a vontade de saber. Rio de Janeiro: Graal.

, (2000). Sobre a história da sexualidade. In: FouCAuLT, M. Microfísica do poder. Rio de Janeiro: Graal, p. 243-276.

GOLDMAN-AMIRAV, A., (1996). "Mira, Yahveh me ha hecho estéril”. In: TUBERT, S. (ed.). Figuras de la madre. Madrid: Cátedra, p. 41-51.

LARROSA, J., (1995). Tecnologias do eu e educação. In: SILVA, T. T. da (org.). O sujeito da educação: estudos foucaultianos. Petrópolis: Vozes, p. 35-86.

MÃES: histórias que a vida conta, (2001). Crescer, São Paulo, $\mathrm{n}^{\circ}$ 86, p. 40-43, jan. 
O DESAFIO do excesso do peso, (2001). Crescer, São Paulo, ${ }^{\circ}$ 89 , p. $20-23$, abr.

O NOVO look de Xuxa, (2000). Caras, São Paulo, edição 341, 19 maio.

O RETIRO de Vera Fischer, (1998). Caras, São Paulo, edição 225 , ano $5, n^{\circ} 9,27$ fev.

SASHA invade palco e faz surpresa à mamãe Xuxa, (2001). Caras, São Paulo, edição 392, 11 maio.

SHOW de Sasha em Angra, (2000). Caras, São Paulo, edição 330, 3 mar.
XUXA Meneghel vai às compras, (1998a). Caras, São Paulo, edição 221, ano 5, n $\mathrm{n}^{\mathrm{O}}$ 5, 30 jan.

XUXA comanda baile dos baixinhos, (1998b). Caras, São Paulo, edição 225, ano 5, nº 9, 27 fev.

XUXA supera ansiedades e revela seus sonhos em Acapulco, (1999). Caras, São Paulo, edição 291, ano 6, nº 23, 4 jun.

XUXA: "Eu estou namorando", (2002). Caras, São Paulo, edição 450 , ano $9, n^{\circ} 25,21$ jun.

Recebido em outubro de 2004 Aprovado em maio de 2005 


\section{Resumos/Abstracts}

\section{Fabiana de Amorim Marcello}

Enunciar-se, organizar-se, controlar-se: modos de subjetivação feminina no dispositivo da maternidade

Objetiva analisar de que maneira o dispositivo da maternidade é organizado na mídia de forma a produzir modos de subjetivação feminina específicos. Com base em um referencial foucaultiano, caracterizo enunciar-se, organizar-se e controlar-se como técnicas de si efetuadas pelos sujeitos-mãe. Assim, realizo uma análise discursiva de dois conjuntos de materiais: um, composto por reportagens das revistas Veja e Caras, de 1992 a 2002, sobre "mães-famosas" (Cássia Eller, Luciana Gimenez, Vera Fischer e Xuxa); e outro, composto pela revista Crescer, no período de janeiro de 2001 a julho de 2002. Mostro como esse dispositivo organiza essas técnicas de si de modo a criar uma lógica em que o indivíduo-mãe é convidado a voltar-se para si mesmo e considerar que cuidar de si é cuidar do outro (seu filho), e no sentido de levar os indivíduos-mãe a se reconhecerem como objetos visíveis a si mesmos e a se enunciarem como sujeitos transformados pela prática materna.

Palavras-chave: dispositivo; maternidade; mídia; modos de subjetivação

\section{Enunciating, organising and controlling oneself: modes of female subjectivation}

The purpose of this article is to analyse the way in which the motherhood role is organised in the media, producing specific modes of female subjectivation. Based on a Foucaultian framework, I characterise enunciating oneself, organising oneself and controlling oneself as techniques of the self used by the mother-subjects. I thus undertake a discursive analysis of two sets of materials: one consisting of articles from the magazines Veja and Caras, from 1992 to 2002, about "famous mothers" (Cássia Eller, Luciana Gimenez, Vera Fischer and Xuxa); and, the other, consisting of articles published in the magazine Crescer, between January 2001 and July 2002. I show how this mechanism organises these techniques of the self in order to create a logic where the mother-individual is asked to focus on herself and consider that taking care of herself is taking care of the other (her son) and, in this way, leading the mother-individuals to recognise themselves as objects visible to themselves and to enunciate themselves as subjects transformed by maternal practices.

Key-words: mechanism; motherhood; media; modes of subjectivation 